Jpn. J. Cancer Res. 89, 768-774, July 1998

\title{
Applicability of Combination with Tirapazamine in Boron Neutron Capture Therapy
}

\author{
Shin-ichiro Masunaga, ${ }^{1,4}$ Koji Ono, ${ }^{1}$ Yoshinori Sakurai, ${ }^{2}$ Hitoshi Hori, ${ }^{3}$ Tooru Kobayashi, ${ }^{2}$ \\ Masao Takagaki, ${ }^{1}$ Minoru Suzuki, ${ }^{1}$ Yuko Kinashi ${ }^{1}$ and Mitsuhiko Akaboshi ${ }^{2}$ \\ ${ }^{1}$ Radiation Oncology Research Laboratory and ${ }^{2}$ Division of Radiation Life Science, Research Reactor \\ Institute, Kyoto University, Noda, Kumatori-cho, Sennan-gun, Osaka 590-0494 and Department of Bio- \\ logical Science and Technology, Faculty of Engineering, University of Tokushima, 2-1 Minamijosan- \\ jima-cho, Tokushima 770-8506
}

SCC VII tumor-bearing mice were continuously given 5-bromo-2'-deoxyuridine (BrdU) to label all proliferating cells. After injection of tirapazamine (TPZ), a bioreductive agent, combined with sodium borocaptate ${ }^{10} \mathrm{~B}(\mathrm{BSH})$ or $d l$-p-boronophenylalanine $-{ }^{10} \mathrm{~B}$ (BPA) administration, the tumors were irradiated with thermal neutrons, and then isolated and incubated with cytochalasin-B (a cytokinesis blocker). The micronucleus (MN) frequency in cells without BrdU labeling (quiescent (Q) cells) was determined by means of immunofluorescence staining for BrdU, and that for total cells was obtained from tumors not pretreated with BrdU. Even when no ${ }^{10} B$-compound was administered, TPZ increased the MN frequency of tumor cells including $Q$ cells, resulting in reduction of the difference in $\mathrm{MN}$ frequency between total and $\mathrm{Q}$ cells, mainly by increasing the MN frequency of $Q$ cells. TPZ increased the MN frequency of $Q$ cells when combined with BPA administration, but TPZ showed no apparent effect on each cell population when combined with BSH. Namely, TPZ reduced the difference in MN frequency between total and $Q$ cells caused by ${ }^{10} \mathrm{~B}$-compound administration, especially when BPA was administered. From the viewpoint of the overall cell killing effect in boron neutron capture therapy (BNCT), combination with TPZ appeared to be useful in BPA-BNCT, but not in BSH-BNCT.

Key words: Quiescent cell - Boron neutron capture therapy - Sodium borocaptate- ${ }^{10} \mathrm{~B}-d l-p$ Boronophenylalanine- ${ }^{10} \mathrm{~B}$ - Tirapazamine

Boron neutron capture therapy (BNCT) is based on the reaction that occurs between the ${ }^{10} \mathrm{~B}$ nucleus and thermal neutrons, and represents a promising modality for selective irradiation of tumor tissue. ${ }^{10} \mathrm{~B}$ nuclei capture slow "thermal" neutrons preferentially, and upon capture promptly undergo nuclear fission. The heavy charged particles produced by this ${ }^{10} \mathrm{~B}(\mathrm{n}, \alpha)^{7} \mathrm{Li}$ reaction have ranges of $\approx 9 \mu \mathrm{m}$ and $\approx 5 \mu \mathrm{m}$, respectively, in tissue and have a high relative biological effectiveness for controlling tumor growth as compared with $\gamma$ radiation. ${ }^{1)}$

Meanwhile, recent studies have suggested that tumor hypoxia could be exploited by the use of bioreductive agents which preferentially kill hypoxic cells. ${ }^{2,3)}$ Brown and colleagues reported that tirapazamine (TPZ, SR 4233, WIN 59075, 3-amino-1,2,4-benzotriazine-1,4-dioxide) showed highly selective toxicity toward hypoxic cells in both in vitro and in vivo murine tumor systems. ${ }^{4,5)}$ Severe hypoxia was not required and the level of hypoxia found in many human tumors was sufficient for toxicity. ${ }^{6}$

Many tumor cells do not proliferate (i.e., are quiescent) in situ, but are still clonogenic. ${ }^{7)}$ To improve the effectiveness of cancer treatment, it is necessary to determine the

${ }^{4}$ To whom reprint requests and all correspondence should be addressed. response of quiescent (Q) tumor cells to treatment. Although the nature of $Q$ cells has been studied over the last 30 years, many aspects of these cells are still unknown. ${ }^{7)} \mathrm{Q}$ cells are more likely to be hypoxic, ${ }^{8)}$ and therefore more sensitive to TPZ. ${ }^{9)}$

In analyzing the response of $\mathrm{Q}$ cells in solid tumors, we have developed a combined method with micronucleus $(\mathrm{MN})$ frequency assay and identification of proliferating (P) cells by 5-bromo-2'-deoxyuridine (BrdU) and antiBrdU monoclonal antibody, since a simple method for detecting the response of intratumor $\mathrm{Q}$ cells directly has not been available. ${ }^{10)}$ With this method, we evaluated the usefulness of TPZ injection combined with ${ }^{10} \mathrm{~B}$-compound administration in BNCT for murine solid tumors. Neutron capture reaction was performed with two ${ }^{10} \mathrm{~B}$-compounds, sodium borocaptate- ${ }^{10} \mathrm{~B}(\mathrm{BSH})$ and $d l$-p-boronophenylalanine- ${ }^{10} \mathrm{~B}$ (BPA), which are widely used clinically in Japan. ${ }^{1)}$

\section{MATERIALS AND METHODS}

Tumors, mice, and labeling with BrdU SCC VII squamous cell carcinoma was maintained in vitro in Eagle's minimum essential medium containing $12.5 \%$ fetal bovine serum. Cells were collected from monolayer cultures, and 
approximately $1.0 \times 10^{5}$ cells were inoculated subcutaneously into the left hind legs of 8- to 11-week-old syngeneic female $\mathrm{C} 3 \mathrm{H} / \mathrm{He}$ mice. Nine days after inoculation, mini-osmotic pumps (Alzet model 2001, Polo Alto, CA) containing BrdU dissolved in physiological saline (250 $\mathrm{mg} / \mathrm{ml}$ ) were implanted subcutaneously for 5 days of continuous labeling. Administration of $\mathrm{BrdU}$ did not change the tumor growth rate. The tumors were $1 \mathrm{~cm}$ in diameter at treatment. The labeling index after 5 days of continuous labeling with $\mathrm{BrdU}$ was $55.3 \pm 4.5 \%$, and reached a plateau at this stage. Therefore, in this study, we regarded tumor cells not incorporating BrdU after continuous labeling as Q cells.

Treatment Lithium fluoride thermoplastic boxes capable of holding three mice were made. BrdU-labeled tumorbearing legs were pulled out of the box through a narrow slit in the front, and fixed with adhesive tapes. Twenty minutes after intraperitoneal injection of BSH (125 $\mathrm{mg} \cdot \mathrm{kg}^{-1}$ ) dissolved in physiological saline or $3 \mathrm{~h}$ after oral administration of BPA $\left(1,500 \mathrm{mg} \cdot \mathrm{kg}^{-1}\right)$ also dissolved in physiological saline, the tumors were irradiated with a neutron beam generated by Kyoto University Reactor (KUR). ${ }^{11)}$ For combination with TPZ, TPZ $\left(50 \mathrm{mg} \cdot \mathrm{kg}^{-1}\right)$ dissolved in phosphate-buffered saline (PBS) was intraperitoneally injected $30 \mathrm{~min}$ before neutron irradiation. We used thermal neutron beams with a cadmium ratio of more than 5,000. Therefore, the amount of contaminating fast neutrons was considered to be negligible. The neutron fluence was measured by radioactivation of gold foil at both the front and back of tumors. $\gamma$-Ray doses, including secondary $\gamma$-rays, were measured with thermoluminescence dosimeter powder at the back of tumors. Since the tumors were small and located just beneath the surface, intratumor neutron fluence was assumed to decrease linearly from the front to back of the tumors. Thus, we used the averaged neutron fluence from the measured values at the front and back of tumors. The average neutron fluence and $\gamma$-ray dose rate were $(7.54 \pm 1.89) \times 10^{9} \mathrm{n} \cdot \mathrm{cm}^{-2} \cdot \mathrm{s}^{-1}$ and $(1.72 \pm 0.56) \times 10^{-3} \mathrm{~Gy} \cdot \mathrm{s}^{-1}$ at $5 \mathrm{MW}$, respectively.

On the other hand, each treatment group also included mice that were not pretreated with BrdU.

${ }^{10} \mathrm{~B}$ concentrations were determined in some tumors that were not irradiated. The ${ }^{10} \mathrm{~B}$ concentration in the tumors was measured by prompt $\gamma$-ray spectrometry using a thermal neutron guide tube at KUR. ${ }^{12)}$

Hori synthesized TPZ according to the established method, ${ }^{13)}$ which Brown and colleagues also employed, ${ }^{5)}$ and analyzed it by using chemical ionization mass spectrometry $[\mathrm{m} / \mathrm{z}, 179(\mathrm{MH}+)]$, electron ionization mass spectrometry $[\mathrm{m} / \mathrm{z}, 178(\mathrm{M}+)]$ and infrared spectrometry $[\mathrm{KBr}]$. This synthesized TPZ was concluded to be identical with commercial TPZ. According to an in vivo experimental report, ${ }^{14)} \mathrm{TPZ}$ was administered at a dose $\left(=50 \mathrm{mg} \cdot \mathrm{kg}^{-1}\right)$ close to its maximum tolerated dose, defined as the high- est dose which produced no overt signs of toxicity. The interval between TPZ administration and irradiation $(=30$ $\min$ ) has been shown to be the timing producing a nearmaximum enhancement of radiation cell killing in SCC VII carcinoma. ${ }^{15)}$

Immunofluorescence staining of BrdU-labeled cells and observation of micronucleus formation These procedures have been described in detail elsewhere. ${ }^{10)}$ After the above treatments, tumors excised from mice given BrdU were minced and trypsinized at $37^{\circ} \mathrm{C}$ for $15 \mathrm{~min}$, using $0.05 \%$ trypsin and $0.02 \%$ ethylenediaminetetraacetic acid. Tumor cell suspensions were inoculated into $60-\mathrm{mm}$ tissue culture dishes containing $5 \mathrm{ml}$ of complete medium and $1.0 \mu \mathrm{g} \cdot \mathrm{ml}^{-1}$ of cytochalasin-B to inhibit cytokinesis while allowing nuclear division. The proportion of binuclear cells reached a maximum $48 \mathrm{~h}$ and $72 \mathrm{~h}$ after initiation of culture for total and $\mathrm{Q}$ cell populations, respectively. The cultures were trypsinized and single-cell suspensions were fixed with $70 \%$ ethanol. After centrifugation, the cell pellets were resuspended in $0.4 \mathrm{ml}$ of cold Carnoy's fixative (three volumes of ethanol and one volume of acetic acid). The suspensions $(30 \mu \mathrm{l})$ were then placed on glass microscope slides using a dropper and dried at room temperature. The slides were treated with 2 $N$ hydrochloric acid for $30 \mathrm{~min}$ at room temperature to dissociate the histones and partially denature the DNA. The slides were then immersed in borax-borate buffer $(\mathrm{pH}$ 8.5) to neutralize the acid. BrdU-labeled cells were detected by indirect immunofluorescence staining using monoclonal anti-BrdU antibody and fluorescein isothiocyanate (FITC)-conjugated anti-mouse IgG. To observe the double-staining of tumor cells with FITC and propidium iodide (PI), cells on the slides were treated with $30 \mu \mathrm{l}$ of PI (1-5 $\mu \mathrm{g} \cdot \mathrm{ml}^{-1}$ in PBS) and monitored under a fluorescence microscope. The MN frequency in BrdU-unlabeled cells $(=\mathrm{Q}$ cells) could be examined by counting the micronuclei in those binuclear cells that showed only red fluorescence. The MN frequency was defined as the ratio of the number of micronuclei in the binuclear cells to the total number of binuclear cells observed. ${ }^{16,17)}$ The ratio obtained in tumors not pretreated with BrdU indicated the $\mathrm{MN}$ frequency of all phases of the total tumor $(\mathrm{P}+\mathrm{Q})$ cell populations. More than 300 binuclear cells were counted to determine the MN frequency.

Four mice were used for each set of conditions, and each experiment was repeated 3 times. To examine the differences between pairs of values, Student's $t$ test was used when the variances of the two groups could be assumed to be equal; otherwise the Welch $t$ test was used.

\section{RESULTS}

The ${ }^{10} \mathrm{~B}$ concentrations in tumors in the BSH and BPA administration groups were $10.2 \pm 1.3 \mu \mathrm{g} \cdot \mathrm{g}^{-1}$ and $10.4 \pm 2.3$ 
Table I. Micronucleus Frequency without Neutron Irradiation

\begin{tabular}{lcc}
\hline \hline & Total tumor cells & Quiescent cells \\
\hline No drug & $0.025 \pm 0.003^{\mathrm{a}}$ & $0.053 \pm 0.004$ \\
$\mathrm{TPZ}^{\mathrm{b})}$ & $0.040 \pm 0.019$ & $0.069 \pm 0.021$ \\
$\mathrm{BSH}^{\mathrm{c})}$ & $0.034 \pm 0.004$ & $0.071 \pm 0.010$ \\
$\mathrm{BPA}^{\mathrm{d})}$ & $0.048 \pm 0.009$ & $0.068 \pm 0.010$ \\
$\mathrm{BSH}+\mathrm{TPZ}$ & $0.110 \pm 0.042$ & $0.121 \pm 0.045$ \\
$\mathrm{BPA}+\mathrm{TPZ}$ & $0.098 \pm 0.035$ & $0.111 \pm 0.039$ \\
\hline
\end{tabular}
a) Mean \pm 1 SD.
b) Tirapazamine.
c) Sodium borocaptate- ${ }^{10} \mathrm{~B}$.
d) $d l$-p-Boronophenylalanine- ${ }^{10} \mathrm{~B}$.

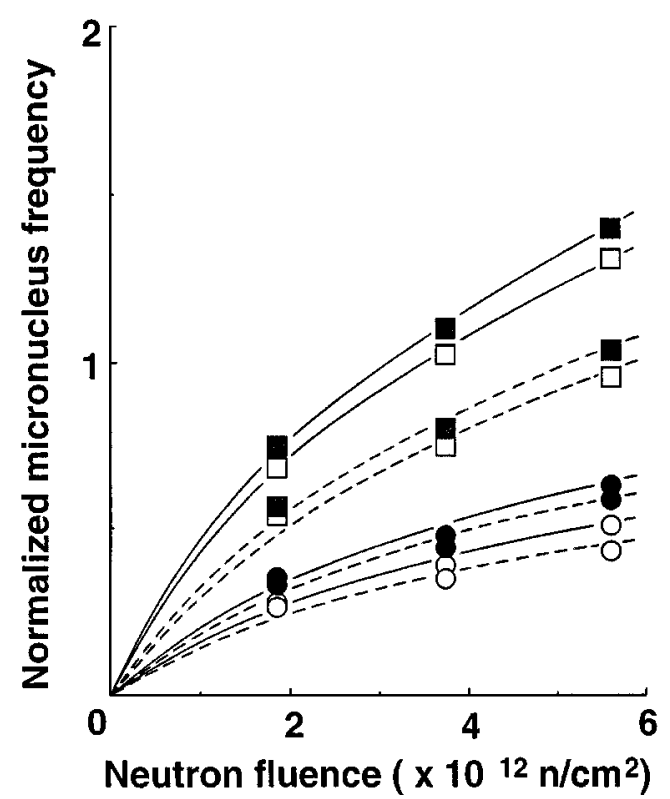

Fig. 1. Dose-response curves for normalized micronucleus $(\mathrm{MN})$ frequency (MN frequency- $C$, where $C$ is the $\mathrm{MN}$ frequency in cells from tumors in nonirradiated animals) of tumors treated with BSH (sodium borocaptate- ${ }^{10} \mathrm{~B}$ ) and/or TPZ (tirapazamine). To avoid confusion, only mean values are shown. In BSH-treated tumors and in those treated with BSH and TPZ, there were significant differences between total tumor cells and $\mathrm{Q}$ cells $(P<0.05)$. In each cell population, $\mathrm{BSH}$ treatment and combined treatment with BSH and TPZ produced significant increases in normalized $\mathrm{MN}$ frequencies $(P<0.05)$. In $\mathrm{Q}$ cells, TPZ treatment produced a significant increase in normalized MN frequency $(P<0.05)$, but with the addition to BSH treatment, the increase by addition of TPZ was not significant. Total cells: $\longrightarrow$ - $\square \square$ TPZ $(-)$; - - $\longrightarrow$ $\mathrm{BSH}(-) ;-\square-, \rightarrow-\mathrm{BSH}(+)$. Q cells: --০--,--口-- TPZ(-);

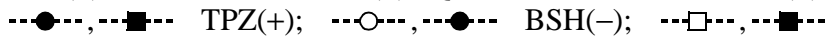
$\mathrm{BSH}(+)$.

$\mu \mathrm{g} \cdot \mathrm{g}^{-1}$, respectively, and this difference was not significant. Table I shows the MN frequencies without neutron radiation for total tumor cells and for $\mathrm{Q}$ cells. With or

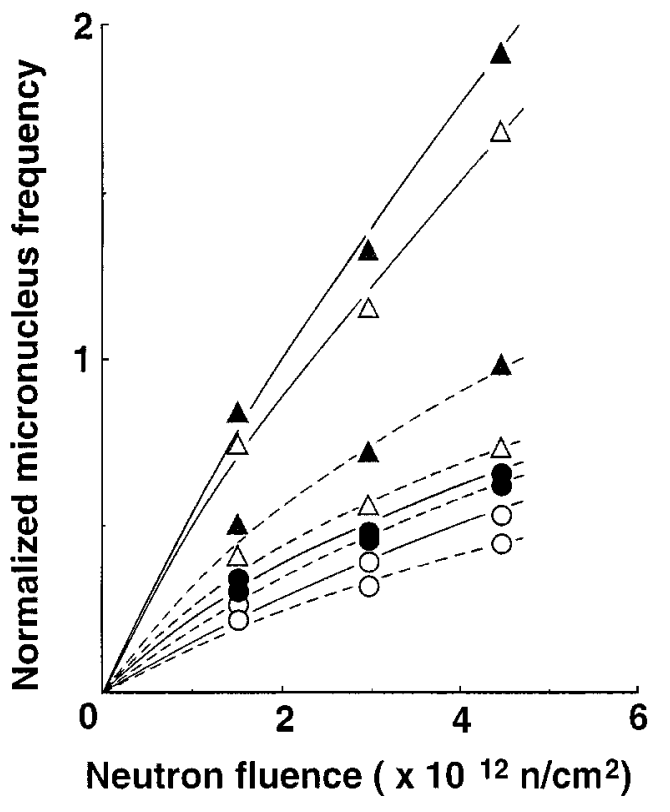

Fig. 2. Dose-response curves for normalized micronucleus (MN) frequency (MN frequency- $C$, where $C$ is the $\mathrm{MN}$ frequency in cells from tumors in nonirradiated animals) of tumors treated with BPA ( $d l-p$-boronophenylalanine- $\left.{ }^{10} \mathrm{~B}\right)$ and/or TPZ (tirapazamine). To avoid confusion, only mean values are shown. In BPA-treated tumors and in those treated with BPA and TPZ, there were significant differences between total tumor cells and $\mathrm{Q}$ cells $(P<0.05)$. In each cell population, BPA treatment and combined treatment with BPA and TPZ produced significant increases in normalized $\mathrm{MN}$ frequencies $(P<0.05)$. With the exception of the total tumor cells from tumors treated with both BPA and TPZ, TPZ treatment produced significant increases in normalized $\mathrm{MN}$ frequency in each cell population regardless of combination with BPA treatment $(P<0.05)$. Total

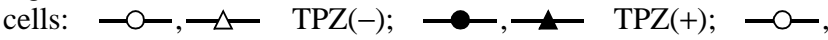
$\longrightarrow \operatorname{BPA}(-) ;-\backsim, \longrightarrow \operatorname{BPA}(+)$. Q cells: $--0--,--\triangle--$

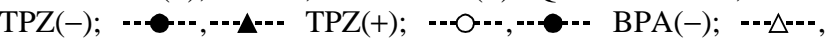
$---\triangle--\operatorname{BPA}(+)$.

without drugs, the $\mathrm{MN}$ frequency of $\mathrm{Q}$ cells was higher than that of total cells when no neutrons were delivered.

Figs. 1 and 2 show the changes in the normalized $\mathrm{MN}$ frequency of each cell population treated with either BSH (Fig. 1), or BPA (Fig. 2), in combination with TPZ administration. When a drug was administered before tumor excision, even if no radiation was applied, the MN frequency was higher than when no drug was administered because of the genotoxicity of the drug (Table I). Therefore, for baseline correction, we used the normalized MN frequency to exclude the effects of genotoxicity of the drug on the MN frequency. The normalized MN frequency was the $\mathrm{MN}$ frequency in the irradiated tumors minus the $\mathrm{MN}$ frequency in the nonirradiated tumors. 
Table II. Neutron Fluence Modifying Factors ${ }^{\text {a) }}$ for Quiescent Cells Relative to the Total Tumor Cells

\begin{tabular}{lcccc}
\hline \hline Normalized MN freq. ${ }^{\mathrm{b})}$ & No drug & ${ }^{10} \mathrm{~B}$-compound & $\mathrm{TPZ}^{\mathrm{c})}$ & $\begin{array}{c}{ }^{10} \mathrm{~B}-\mathrm{compound}+ \\
\mathrm{TPZ}\end{array}$ \\
\hline${ }^{10} \mathrm{~B}$-compound=BSH ${ }^{\mathrm{d})}$ & - & $1.7(1.5-1.9)^{\mathrm{e})}$ & - & $1.7(1.5-1.9)$ \\
1.0 & - & $1.7(1.5-1.9)$ & - & $1.6(1.5-1.7)$ \\
0.8 & $1.2(1.1-1.3)$ & $1.6(1.4-1.8)$ & $1.1(1.0-1.2)$ & $1.5(1.4-1.6)$ \\
0.4 & $1.2(1.1-1.3)$ & $1.6(1.4-1.8)$ & $1.1(1.0-1.2)$ & $1.5(1.4-1.6)$ \\
0.2 & & & & \\
${ }^{10} \mathrm{~B}-$ compound=BPA ${ }^{\mathrm{f})}$ & - & - & - & $2.1(1.7-2.5)$ \\
0.8 & $1.3(1.2-1.4)$ & $2.2(2.0-2.4)$ & $1.2(1.1-1.3)$ & $1.8(1.6-2.0)$ \\
0.4 & $1.3(1.2-1.4)$ & $2.0(1.8-2.2)$ & $1.2(1.1-1.3)$ & $1.6(1.4-1.8)$ \\
0.2 & & & & \\
\hline
\end{tabular}

a) Neutron fluence required to obtain each normalized micronucleus frequency in quiescent cells in relation to that required to obtain each normalized micronucleus frequency in total cells.

b) Normalized micronucleus frequency, micronucleus frequency minus the micronucleus frequency in unirradiated tumors.

c) Tirapazamine.

d) Sodium borocaptate- ${ }^{10} \mathrm{~B}$

e) Ninety-five percent confidence limits.

f) $d l-p$-Boronophenylalanine- ${ }^{10} \mathrm{~B}$.

Table III. The Effects of TPZ ${ }^{\text {a) }}$ on Neutron Fluence Ratio ${ }^{\text {b) }}$

\begin{tabular}{|c|c|c|c|c|}
\hline \multirow{2}{*}{ Normalized MN freq. ${ }^{c}$} & \multicolumn{2}{|c|}{ Total tumor cells } & \multicolumn{2}{|c|}{ Quiescent cells } \\
\hline & No drug & ${ }^{10} \mathrm{~B}$-compound & No drug & ${ }^{10} \mathrm{~B}$-compound \\
\hline \multicolumn{5}{|l|}{${ }^{10} \mathrm{~B}$-compound=BSH ${ }^{\mathrm{d})}$} \\
\hline 1.0 & - & $1.1(1.0-1.2)^{\mathrm{e})}$ & - & $1.2(1.0-1.4)$ \\
\hline 0.8 & - & $1.1(1.0-1.2)$ & - & $1.1(1.0-1.2)$ \\
\hline 0.4 & $1.4(1.2-1.6)$ & $1.1(1.0-1.2)$ & $1.6(1.4-1.8)$ & $1.1(1.0-1.2)$ \\
\hline 0.2 & $1.2(1.1-1.3)$ & $1.2(1.0-1.4)$ & $1.4(1.2-1.6)$ & $1.2(1.0-1.4)$ \\
\hline \multicolumn{5}{|l|}{${ }^{10} \mathrm{~B}-$ compound $=\mathrm{BPA}^{\mathrm{f})}$} \\
\hline 0.8 & - & $1.2(1.0-1.4)$ & - & - \\
\hline 0.4 & $1.4(1.2-1.6)$ & $1.1(1.0-1.2)$ & $1.6(1.4-1.8)$ & $1.4(1.3-1.5)$ \\
\hline 0.2 & $1.4(1.2-1.6)$ & $1.1(1.0-1.2)$ & $1.6(1.4-1.8)$ & $1.3(1.2-1.4)$ \\
\hline
\end{tabular}

a) Tirapazamine.

b) Ratio of neutron fluence required to obtain each normalized micronucleus frequency without TPZ in relation to the neutron fluence required to obtain each normalized micronucleus frequency with TPZ.

c) Normalized micronucleus frequency, micronucleus frequency minus the micronucleus frequency in unirradiated tumors.

d) Sodium borocaptate- ${ }^{10} \mathrm{~B}$.

e) Ninety-five percent confidence limits.

f) $d l-p$-Boronophenylalanine- ${ }^{10} \mathrm{~B}$.

With or without ${ }^{10} \mathrm{~B}$-compounds, the normalized $\mathrm{MN}$ frequency of $\mathrm{Q}$ cells was lower than that of the total tumor cells. Under each irradiation condition, neutron fluence modifying factors, which compare the neutron fluence required to obtain various normalized $\mathrm{MN}$ frequencies in $\mathrm{Q}$ cells with that in the total tumor cells, were calculated using the values of the data in Figs. 1 and
2 (Table II). The use of ${ }^{10} \mathrm{~B}$-compounds increased the difference in normalized $\mathrm{MN}$ frequency between total and $\mathrm{Q}$ cells, especially when BPA was used. TPZ injection reduced the difference in $\mathrm{MN}$ frequency between total and $\mathrm{Q}$ cells induced by ${ }^{10} \mathrm{~B}$-compound administration, especially in the case of administration of BPA. TPZ treatment alone also reduced the difference in $\mathrm{MN}$ frequency 


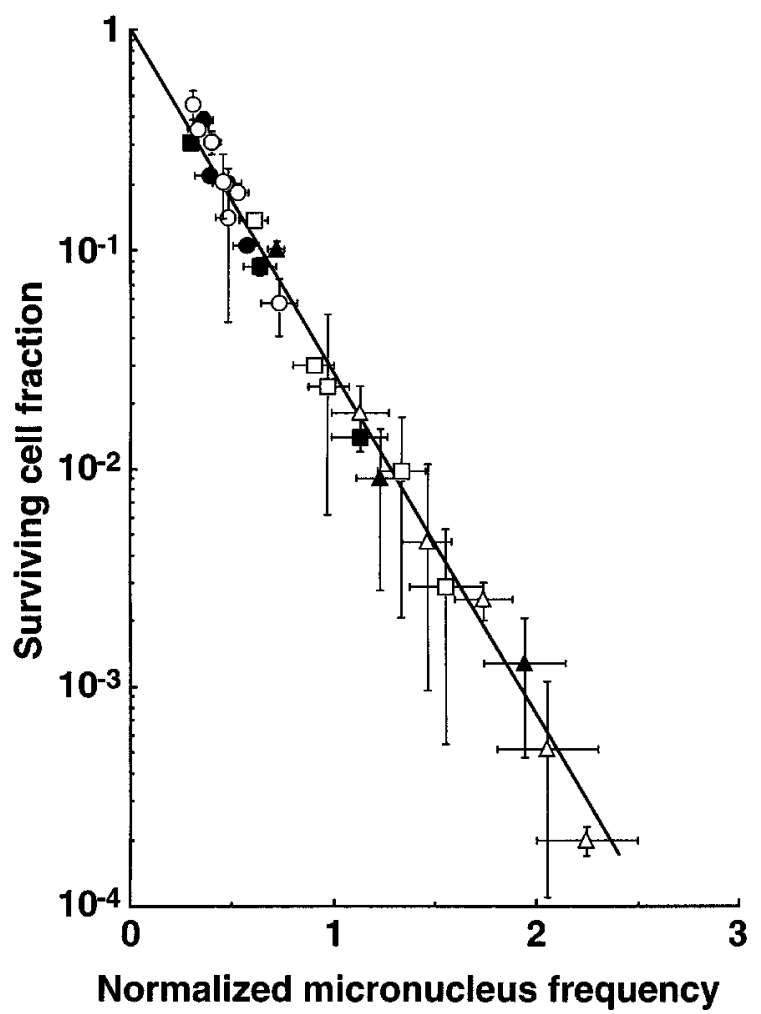

Fig. 3. Correlation between normalized micronucleus (MN) frequency and surviving fraction for each of 6 conditions in total cell populations of SCC VII tumors. The 6 regression lines were statistically identical $(P<0.05)$. The regression line calculated from all these data was $\ln Y=-3.60 X(X=$ normalized $\mathrm{MN}$ frequency, $Y=$ surviving fraction), and a significant positive correlation of $r=-0.98$ was observed $(P<0.001)$. Thus, there is a close relationship between $\mathrm{MN}$ frequency and surviving fraction, and the sensitivity of SCC VII tumor cells to neutron capture irradiation can be expressed in terms of the MN frequency instead of surviving fraction. Bars represent SDs. $O{ }^{10} \mathrm{~B}$-compound(-) $\mathrm{TPZ}(-) ; \square \mathrm{BSH}(+) \mathrm{TPZ}(-) ; \triangle \mathrm{BPA}(+) \mathrm{TPZ}(-) ; \bullet{ }^{10} \mathrm{~B}-\mathrm{com}-$ pound(-) $\mathrm{TPZ}(+)$; $\mathrm{BSH}(+) \mathrm{TPZ}(+) ; \boldsymbol{\Delta} \mathrm{BPA}(+) \mathrm{TPZ}(+)$. TPZ, tirapazamine; $\mathrm{BSH}$, sodium borocaptate- ${ }^{10} \mathrm{~B} ; \mathrm{BPA}, d l-p$ boronophenylalanine- ${ }^{10} \mathrm{~B}$.

between total and Q cells observed when no drugs were administered, mainly by increasing the MN frequency of Q cells.

To evaluate the effects of TPZ on the MN frequency in total and Q cells, the enhancement ratio (ER) by TPZ was calculated at various normalized $\mathrm{MN}$ frequencies using the data shown in Figs. 1 and 2 (Table III). TPZ enhanced the sensitivity of tumor cells, including $\mathrm{Q}$ cells, even when no ${ }^{10} \mathrm{~B}$-compound was administered. In combination with ${ }^{10} \mathrm{~B}$-compound, all ER values decreased. However, TPZ showed a greater effect on Q cells when BPA was administered, while it had no apparent effect on each cell population when BSH was administered.

\section{DISCUSSION}

Previously Ono et al. ${ }^{18)}$ showed that more than $90 \%$ of SCC VII tumor cells divide at least once following neutron capture irradiation and that the probability of completing the first post-treatment mitosis was almost equivalent in SCC VII cells regardless of neutron capture compound administration. In addition, our preliminary experiment showed that, in total cell populations of SCC VII tumors, the correlations between normalized MN frequency and the surviving fraction under 6 conditions could be expressed as one regression line whether the cells were irradiated with or without drugs (Fig. 3). Consequently, the sensitivity of tumor cells to neutron capture irradiation was thought to be reflected reasonably well by their normalized MN frequency, instead of by their loss of clonogenicity.

It was shown that the profile of cytotoxicity of TPZ as a function of the oxygen concentration is different from those of other bioreductive agents. ${ }^{2}{ }^{2}$ Mitomycin $\mathrm{C}$ exhibits weak selective toxicity under hypoxic conditions, and extremely low levels of oxygen are required to obtain maximum cytotoxicity. ${ }^{2)}$ TPZ maintains its "hypoxic cytotoxicity" at oxygen concentrations approximately 10 -fold higher than nitroimidazole bioreductive agents. ${ }^{6}$ We previously found that within SCC VII tumors Q cells include a larger hypoxic fraction than the total cells (Q cells: $53 \pm 2 \%$ vs total cells: $11 \pm 2 \%){ }^{10)}$ Therefore, TPZ showed a greater cytotoxicity to $\mathrm{Q}$ cells than to the total cells (Table III). Hence, TPZ treatment alone could reduce the difference in $\mathrm{MN}$ frequency between total and Q cells observed after neutron irradiation without a ${ }^{10} \mathrm{~B}$-compound (Table II).

Meanwhile, ${ }^{10} \mathrm{~B}$-compounds increased the sensitivity of both $\mathrm{Q}$ and total cell populations, especially that of total cells (Figs. 1 and 2); i.e., the difference in sensitivity between total and $\mathrm{Q}$ cells was widened by a ${ }^{10} \mathrm{~B}-\mathrm{com}$ pound (Table II). In our previous report, ${ }^{19)}$ we suggested that this event was induced mainly because Q cells could not take up ${ }^{10} \mathrm{~B}$ as efficiently as $\mathrm{P}$ cells.

Solid tumors, especially human tumors, are thought to contain a high proportion of $\mathrm{Q}$ cells. ${ }^{20)}$ The presence of these cells is probably due, in part, to hypoxia and nutrition depletion in the tumor core, and this is another consequence of poor vascular supply. ${ }^{7)}$ Therefore, $\mathrm{Q}$ cells may have higher $\mathrm{MN}$ frequencies at $0 \mathrm{~Gy}$ than the total cell population (Table I), and Q cells could be more sensitive to the hypoxia-specific cytotoxin TPZ even when combined with ${ }^{10} \mathrm{~B}$-compound administration (Table III). However, once ${ }^{10} \mathrm{~B}$ is distributed in tumor cells, ${ }^{10} \mathrm{~B}$ itself could enhance their sensitivity much more markedly than TPZ because of the heavily charged high linear energy transfer particles produced by neutron capture reaction (Figs. 1 and 2). Therefore, TPZ could show larger ERs for Q cells 
than for total cells, especially when BPA, which showed a poorer distribution in $\mathrm{Q}$ cells than $\mathrm{BSH},{ }^{19}$ ) was administered (Table III). Consequently, TPZ could reduce the difference in $\mathrm{MN}$ frequency between total and $\mathrm{Q}$ cells induced by ${ }^{10} \mathrm{~B}$-compound administration, especially in the case of BPA administration (Table II).

With regard to TPZ effect, the curves of normalized MN frequency according to neutron fluence with and without TPZ were almost parallel (Figs. 1 and 2). Therefore, the effect of TPZ was thought to be additive. Actually, in SCC VII tumor cell cultures, the interaction of TPZ with irradiation was shown to be essentially additive in vitro. ${ }^{21)}$

It has been reported that $\mathrm{Q}$ cells have lower radiosensitivity to photons than $\mathrm{P}$ cells in solid tumors in vivo. ${ }^{7,20)}$ Thus, more $\mathrm{Q}$ cells can survive after radiotherapy than $\mathrm{P}$ cells. Therefore, the control of $\mathrm{Q}$ cells, some of which will still be clonogenic, ${ }^{7)}$ is thought to influence greatly the outcome of anticancer radiotherapy. However, ${ }^{10} \mathrm{~B}-$ compound administration in BNCT expanded the difference in sensitivity between total and Q cells compared with no drug administration (Table II). From the viewpoint of tumor curability, including $\mathrm{Q}$ tumor cell control, the use of TPZ in BNCT appears to be encouraging, even if the TPZ effect is additive. In particular, the combination

\section{REFERENCES}

1) Barth, R. F., Soloway, A. H. and Brugger, R. M. Boron neutron capture therapy of brain tumors: past history, current status, and future potential. Cancer Invest., 14, 534550 (1996).

2) Brown, J. M. and Siim, B. G. Hypoxia-specific cytotoxins in cancer therapy. Semin. Radiat. Oncol., 6, 22-36 (1996).

3) Kennedy, K. A., Teicher, B. A., Rockwell, S. and Sartorelli, A. C. The hypoxic tumor cell: a target for selective cancer chemotherapy. Biochem. Pharmacol., 29, 1-8 (1979).

4) Brown, J. M. SR 4233 (tirapazamine): a new anticancer drug exploiting hypoxia in solid tumours. Br. J. Cancer, 67, 1163-1170 (1993).

5) Zeman, E. M., Brown, J. M., Lemmon, M. J., Hirst, V. K. and Lee, W. W. SR-4233: a new bioreductive agent with high selective toxicity for hypoxic mammalian cells. Int. J. Radiat. Oncol. Biol. Phys., 12, 1239-1242 (1986).

6) Koch, C. J. Unusual oxygen concentration dependence of toxicity of SR-4233, a hypoxic cell toxin. Cancer Res., 53, 3992-3997 (1993).

7) Jackson, R. C. The problem of the quiescent cancer cell. Enzyme Regul., 29, 27-46 (1989).

8) Dethlefsen, L. A. In quest of the quaint quiescent cells. In "Radiation Biology in Cancer Research," ed. R. E. Meyn and H. R. Withers, pp. 415-435 (1980). Raven Press, New York.

9) Sartorelli, A. C. Therapeutic attack of hypoxic cells of of TPZ with BPA may be effective and advantageous. It is now evident that agents that can preferentially kill hypoxic cells constitute another class of agents with a defined use in BNCT, especially in BPA-BNCT.

The characterization of $\mathrm{Q}$ cells in solid tumors and examination of their sensitivity to various treatments has been greatly hampered by the lack of adequate systems to identify $\mathrm{Q}$ cells and to obtain large homogeneous populations of them. Hence, the Q cell assay method used in this study appears to be useful for determining the sensitivity of $\mathrm{Q}$ cell populations in solid tumors to various DNAdamaging treatments. Using this method, we plan to investigate the responses of $\mathrm{Q}$ cells to various anticancer treatments. Further, it is now evident that apoptosis is strongly correlated with the curability of some tumors. ${ }^{22,23)}$ We also plan to assess the effectiveness of neutron capture reaction in inducing apoptosis.

\section{ACKNOWLEDGMENTS}

This work was supported, in part, by Grants-in-Aid for Cancer Research $(08877139,09255229,09670931,10153234)$ from the Ministry of Education, Science, Sports and Culture, Japan.

(Received March 25, 1998/Revised May 22, 1998/Accepted June 3, 1998)

solid tumors: presidential address. Cancer Res., 48, 775778 (1988).

10) Masunaga, S., Ono, K. and Abe, M. A method for selective measurement of the radiosensitivity of quiescent cells in solid tumors-combination of immunofluorescence staining to BrdU and micronucleus assay. Radiat. Res., 125, 243-247 (1991).

11) Kanda, K. An overview: radiation sources, beam quality, dosimetry and spectroscopy in neutron capture therapy. Strahlenther. Onkol., 165, 67-69 (1989).

12) Kobayashi, T., Kanda, K. and Mishima, Y. In situ measurement on ${ }^{10} \mathrm{~B}$ concentrations and absorbed dose estimations in human malignant melanoma treated by BNCT. Strahlenther. Onkol., 165, 104-106 (1989).

13) Seng, F. and Ley, K. Simple synthesis of 3-amino-1,2,4benzotriazine-1,4-dioxide. Angew. Chem. Int. Ed. Engl., 11, 1009-1010 (1972).

14) Bremner, J. C. M., Stratford, I. J., Bowler, J. and Adams, G. E. Bioreductive drugs and the selective induction of tumor hypoxia. Br. J. Cancer, 61, 717-721 (1990).

15) Brown, J. M. and Lemmon, M. J. Potentiation by the hypoxic cytotoxin SR 4233 of cell killing produced by fractionated irradiation of mouse tumors. Cancer Res., 50, 7745-7749 (1990).

16) Ono, K., Wandl, E. O., Tsutsui, K., Sasai, K. and Abe, M. The correlation between cell survival curve and dose response curve of micronucleus (MN) frequency. Strahlen- 
ther. Onkol., 165, 824-827 (1989).

17) Fenech, M. and Morley, A. A. Measurement of micronuclei in lymphocytes. Mutat. Res., 147, 29-36 (1985).

18) Ono, K., Masunaga, S., Kinashi, Y., Takagaki, M., Akaboshi, M., Kobayashi, T. and Akuta, K. Radiobiological evidence suggesting heterogeneous microdistribution of boron compounds in tumors: its relation to quiescent cell population and tumor cure in neutron capture therapy. Int. J. Radiat. Oncol. Biol. Phys., 34, 1081-1086 (1996).

19) Masunaga, S., Ono, K., Suzuki, M., Takagaki, M., Sakurai, Y., Kobayashi, T., Akuta, K., Akaboshi, M., Kinashi, Y. and Abe, M. Modification of the response of a quiescent cell population within a solid tumour to boron neutron capture irradiation: studies with nicotinamide and hyperthermia. Br. J. Radiol., 70, 391-398 (1997).

20) Wallen, C. A., Ridinger, D. N. and Dethlefsen, L. A. Het- erogeneity of X-ray cytotoxicity in proliferating and quiescent murine mammary carcinoma cells. Cancer Res., $\mathbf{4 5}$, 3064-3069 (1985).

21) Shibata, T., Shibamoto, Y., Sasai, K., Oya, N., Takagi, T., Hiraoka, M., Takahashi, M. and Abe, M. Tirapazamine: hypoxic cytotoxicity and interaction with radiation as assessed by the micronucleus assay. Br. J. Cancer, 74 (Suppl. XXVII), S61-S64 (1996).

22) Wheeler, J. A., Stephans, L. C., Tornos, C., Eifel, P. J., Ang, K. K., Milas, L., Allen, P. K. and Meyn, R. E, Jr. ASTRO Research Fellowship: apoptosis as a predictor of tumor response to radiation in stage IB cervical carcinoma. Int. J. Radiat. Oncol. Biol. Phys., 32, 1487-1493 (1995).

23) Denmeade, S. R., Lin, X. S. and Isaacs, J. T. Role of programmed (apoptotic) cell death during the progression and therapy for prostate cancer. Prostate, 28, 251-265 (1996). 